Original Article

\title{
Preventive effects of stretching and stabilization exercises on muscle fatigue in mobile phone users
}

\author{
Hye-Young Kim, $\mathrm{PhD}^{1)}$, Young-Ran Yeun, $\mathrm{PhD}^{2)}$, Sung-Joong Kim, PhD, $\mathrm{PT}^{3)^{*}}$ \\ 1) Department of Dental Hygiene, Kangwon National University, Republic of Korea \\ 2) Department of Nursing, Kangwon National University, Republic of Korea \\ 3) Department of Physical Therapy, Kangwon National University: 3 Hwangjo-ri, Dogye-eup, \\ Samcheok-si, Gangwon-do 245-907, Republic of Korea
}

\begin{abstract}
Purpose] The purpose of this study was to investigate the preventive effects of stretching and stabilization exercises on muscle fatigue of the neck erector spine and upper trapezius muscles. [Subjects and Methods] The subjects of this study were 26 healthy university students (14 males and 12 females). Each subject was assigned randomly to each of three study groups in order to prevent order effect. The three groups included in this study were the no-exercise, stretching exercise, and neck stabilization exercise groups. The median electromyographic frequency was used as a gauge of muscle fatigue. [Results] Decreased muscle fatigue was demonstrated by an increase in the median electromyographic frequency values in all the four muscle groups in the comparison between conditions 1 and 3. In particular, statistically significant differences were found between the two conditions in the right upper trapezius muscle group. [Conclusion] These findings suggest that the effect of stretching and stabilization exercises can reduce muscle fatigue in mobile phone users.

Key words: Mobile phone, Muscle fatigue
\end{abstract}

(This article was submitted Mar. 29, 2016, and was accepted May 23, 2016)

\section{INTRODUCTION}

Mobile phones are one of the most essential items in modern human life. Adult mobile phone usage was found to be one of the most important means of communication in an international study in 2007 ${ }^{1}$. The rapid increase in the frequency of use of mobile phones among adults can adversely affect various aspects of human health, and numerous studies ${ }^{2-4)}$ have investigated such adverse effects, particularly those focused on the neck and arms.

Kapandji ${ }^{5}$ reported that with a head movement of $2.5 \mathrm{~cm}$, an additional weight of $0.4 \mathrm{~kg}$ is imposed on the neck and upper body. Greig et al. ${ }^{6}$ reported that muscle activity is maintained at a maximum of $5 \%$ according to video screen-displayed electromyography (EMG) results from the sternocleidomastoid and upper trapezius muscles. Straker et al. ${ }^{7}$ reported that the neck bends more when an individual is using a tablet with a relatively small screen than when the individual is using a general desktop computer and that muscle activity during tablet use increases in the shoulders and surrounding muscles. This is because video devices with small screens require more bending of the neck (than devices with larger screens) when the extensor digitorum muscles are activated to balance the neck during the lowered gaze, increasing the load on the sternocleidomastoid muscles ${ }^{6,8)}$.

Accumulated long-term and severe fatigue can seriously affect human health ${ }^{9)}$. Such fatigue is an important component of human health and can lead to musculoskeletal injuries and psychological issues. They may become a major cause of neck pain, which is closely correlated to the degrees of fatigue and tension. These injuries can lead to chronic neck pain, resulting

\footnotetext{
*Corresponding author. Sung-Joong Kim (E-mail lymphkim@naver.com)

(C)2016 The Society of Physical Therapy Science. Published by IPEC Inc.

This is an open-access article distributed under the terms of the Creative Commons Attribution Non-Commercial No Derivatives (by-nc-nd) License $<$ http://creativecommons.org/licenses/by-nc-nd/4.0/>.
} 
in serious problems in job performance unless proper treatment is provided.

Ylinen et al. ${ }^{10)}$ reported that stretching exercises alleviate neck pain, thereby increasing the joint range of motion and contributing to an increase in patient quality of life. However, Morgan and Proske ${ }^{11)}$ reported that persistent muscle stretching can damage muscle tissue, without much affecting joint range of motion. Furthermore, muscular strength can be decreased immediately after stretching ${ }^{12)}$, without much increase in muscular strength ${ }^{13)}$.

Previous studies mainly focused on subjects with neck pain rather than on mobile phone users. Thus, this study investigated the effects of stabilization exercises such as stretching and neck exercises on the degree of muscle fatigue resulting from continuous use of mobile phones.

\section{SUBJECTS AND METHODS}

Twenty-six volunteers were enrolled in this study (14 males and 12 females).

All the subjects participated voluntarily and provided written informed consent. Individuals with congenital (hereditary) handicaps, patients with surgical and neurological histories, and patients with severe arm injuries were excluded. The subjects' mean age was $20.1 \pm 0.5$ years; mean height, $165.5 \pm 2.2 \mathrm{~mm}$; and mean weight, $62.1 \pm 4.2 \mathrm{~kg}$. All test protocols were approved by the ethics committee of the Physical Therapy Faculty of Kangwon National University.

The participants used their usual mobile phones in this study. They also used a TeleMyo 2400 direct transmission system for EMG (Noraxon Inc., AZ, USA) with a Noraxon Wi-Fi transmitter to receive and collect surface EMG signals from the sternocleidomastoid and upper trapezius muscles, which provide stability in the shoulder area during phone use ${ }^{14)}$.

In this experiment, surface EMG of the cervical erector spinae and upper trapezius, in which muscle activity increases during cell phone use, was performed during the participants' mobile phone use ${ }^{8)}$. The electrode for measuring the activity of the sternocleidomastoid muscles was attached on a spot $2 \mathrm{~cm}$ from cervical vertebra $4(\mathrm{C} 4)^{15,16)}$, and the electrode for measuring the activity of the upper trapezius muscles was attached on a spot slightly outside the midpoint between cervical vertebra $7(\mathrm{C} 7)$ and the protruding peaks of the shoulder bones ${ }^{17)}$. To prevent unnecessary noise during the EMG measurement, the contact area selected was cleaned with alcohol before attaching the surface electrode to the skin. The reference voluntary contraction (RVC) method was used to quantify the EMG values. The EMG signals were collected while the subject was holding $1 \mathrm{~kg}$ of dumbbells in both hands, with the subject's hands spread out $90^{\circ}$ apart on the wing bone plane, with the subject maintaining the position for 15 seconds. The mean values during the 5 seconds were used as RVC values ${ }^{18)}$.

This study involved repeated, randomized, crossover experiments with the participants in each group and a comparison of the resulting values. The experiments conducted were divided into three different conditions and conducted on different days. On day 1 , the participants used a mobile phone without any intervention to minimize the effects of fatigue from the previous experiment (condition 1). On day 2, the participants did some stretching exercises before using a mobile phone and the measurements were taken while the participants were using their phones (condition 2). On day 3, the participants performed stabilization exercises before phone use (condition 3). These experiments were conducted in random order to avoid order effects.

To equalize all the participants' starting positions before the measurement, the participants were told to sit comfortably with their hip and knee joints bent at $90^{\circ}$ and their feet flat on the floor. Furthermore, they were told to raise their mobile phones up to the level of their clavicle, with their elbow bent to avoid excessive bending of the waist. Once phone use began, they were told to focus on their mobile phone use and ignore their neck and waist positions.

The experimental conditions were as follows: Under condition 1 (the reference group), EMG was performed for 10 minutes while the participants were using the phone without any intervention. Under condition 2 (which included stretching exercises), the participants engaged in a stretching exercise program that was modified from the training method used by Lee and $\mathrm{Yoo}^{19)}$. The participants performed passive stretching exercises in five motions for 10 seconds, each with an upright and fixed posture, as follows: bending forward with the neck pulled forward while standing upright, leaning backward, bending left and right, and turning the neck. Each session was implemented in two sets. Breaks were provided for 10 seconds between the sessions and 5 minutes between the sets. After the stretching exercises, the participants had a 1-minute break before EMG was performed for 10 minutes while they were using a mobile phone.

Under condition 3 (which included stabilization exercises), the participants engaged in a stabilization exercise program that was modified from the training method used by Hur ${ }^{20)}$. These exercises enhance the muscular strength of the long neck and long head muscles (cardiac muscles), and involve the following five motions: isometric contraction exercises for 10 seconds without moving the neck before returning back to the starting position, neck bending exercises in the supine position, neck stretching and greater pectoral muscle stretching exercises in the supine position, upper back muscle-enhancing exercises while lying face down, placing both thumbs underneath the chin while sitting, and leaning against the wall in a standing upright position with the chin pulled in. Five sessions were implemented for 10 seconds each for two sets in total, and breaks were allowed for 10 seconds between the sessions and 5 minutes between the sets. After the stabilization exercises, the participants had a 1-minute break before EMG was performed for 10 minutes while they were using their mobile phones.

Descriptive data are expressed as mean \pm SD values. Testing of all variables using the one-sample Kolmogorov-Smirnov test revealed that they were all normally distributed. A repeated one-way analysis of variance determined the significance of temperature differences between the upright sitting position and sitting with the legs crossed. Scheffe's test was conducted 
as a post hoc test to determine the significance of differences. Statistical analysis was performed by using SPSS 21.0, and a significance level of $\mathrm{p}=0.05$ was used.

\section{RESULTS}

The three conditions were defined as follows: the day the participants used a mobile phone without any intervention (condition 1), the day the participants performed some stretching exercise before using a mobile phone and the measurements were taken while the participants were using their phones (condition 2), and the day the participants performed stabilization exercises before phone use (condition 3). The median frequency values for each condition are shown in Table 1. The median frequency values increased in all the muscle groups in the comparison between conditions 1 and 2, showing a decrease in the degree of fatigue. The decreased fatigue between conditions 1 and 3 was demonstrated by the increase in the median frequency values in all the four muscle groups included in the comparison. In particular, statistically significant differences were found between conditions 1 and 3 in the right upper trapezius muscle group $(p<0.05)$.

\section{DISCUSSION}

Stretching and stabilization exercises are simple and economic programs that anybody can try. However, researchers disagree about their effectiveness, and few studies have compared and analyzed how such exercises when performed prior to using a mobile phone can affect neck and shoulder fatigue.

Thus, this study compared and analyzed the effects of stretching and stabilization exercises before mobile phone use on neck and shoulder muscle fatigue, and further investigated the methods for preventing fatigue induced by mobile phone use. Muscle activity and median EMG frequency values were used to measure fatigue. Previous studies mentioned three methods for measuring median frequency values as follows: the isometric contraction method, the "comparison of reference activity" method, and joint analysis of EMG amplitude and spectrum ${ }^{14)}$. This study used the "comparison of reference activity" method to obtain the median frequency values.

As a result, fatigue decreased in all the four muscle groups when the participants used their mobile phones without any intervention (condition 1). Furthermore, when the participants performed stabilization exercises before phone use (condition 3), fatigue decreased in all the four muscle groups. In particular, statistically significant differences were found at the right upper trapezius muscle group between conditions 1 and $3(\mathrm{p}<0.05)$. The reasons for these results are as follows: stretching exercises increase the inner pressure of the muscles through mild muscle contraction. The rhythmic contraction or mild pressure of the muscles accelerates intravenous blood flow and increases blood circulation, which can improve blood flow and remove fatigue-causing substances ${ }^{21)}$. Neck stabilization exercises had positive effects on the deep neck muscles and increased muscular strength and endurance ${ }^{22}$.

This study has the following limitations: First, the results cannot be generalized to all age groups, as the participants were limited to adult males and females in their twenties. Second, the number of participants was too small to apply the results to the general population. Third, this study investigated only the short-term effects (i.e., one-time stretching and stabilization exercises), excluding the long-term effects, of stretching and stabilization exercises. Lastly, all the study participants were right-handed. However, the correlation between the dominant hand and decreased muscle fatigue was not investigated. In the future, diverse age groups and a greater number of participants, as well as the inclusion of adult males and females in their twenties, need to be considered. Furthermore, detailed studies are needed to compare the variations in changes in muscle fatigue that occur over a longer intervention period and to investigate the correlation between the use of the dominant hand and decreased muscle fatigue. As the potential effects of stretching and stabilization exercises on muscle fatigue and other conditions are great, efforts are needed in the future to secure an identical external environment and a sufficient number of target subjects by using more quantitative and controlled methods that integrate with other factors.

Table 1. Changes in median frequency (unit: $\mathrm{Hz}$ )

\begin{tabular}{lccc}
\hline & Condition 1 & Condition 2 & Condition 3 \\
\hline Right cervical erector spine & $36.1 \pm 6.7$ & $36.6 \pm 11.1$ & $37.4 \pm 10.1$ \\
Left cervical erector spine & $32.2 \pm 4.3$ & $33.1 \pm 5.1$ & $35.1 \pm 11.1$ \\
Right upper trapezius & $29.8 \pm 14.1$ & $32.25 \pm 16.1$ & $44.1 \pm 10.8^{* \dagger}$ \\
Left upper trapezius & $27.3 \pm 12.3$ & $31.1 \pm 14.4$ & $37.2 \pm 15.5$ \\
\hline Data are expressed as mean \pm SD. & & \\
${ }^{*}$ p $<0.05$. & & \\
${ }^{\dagger}$ Significant difference between conditions 1 and 3. &
\end{tabular}




\section{REFERENCES}

1) Kenichi I: Examining the adverse effects of mobile phone use among Japanese adolescents. Keio Commun Rev, 2011, 33: 69-83.

2) Lee S, Lee D, Park J: Effect of the cervical flexion angle during smart phone use on muscle fatigue of the cervical erector spinae and upper trapezius. J Phys Ther Sci, 2015, 27: 1847-1849. [Medline] [CrossRef]

3) Lee J, Seo K: The comparison of cervical repositioning errors according to smartphone addiction grades. J Phys Ther Sci, 2014, 26: 595-598. [Medline] [CrossRef]

4) Jung SI, Lee NK, Kang KW, et al.: The effect of smartphone usage time on posture and respiratory function. J Phys Ther Sci, 2016, 28: 186-189. [Medline] [CrossRef]

5) Kapandji IA: The physiology of the joints, 6th ed. Vol. 3. Churchill Livingstone, 2008.

6) Greig AM, Straker LM, Briggs AM: Cervical erector spinae and upper trapezius muscle activity in children using different information technologies. Physiotherapy, 2005, 91: 119-126. [CrossRef]

7) Straker LM, Coleman J, Skoss R, et al.: A comparison of posture and muscle activity during tablet computer, desktop computer and paper use by young children. Ergonomics, 2008, 51: 540-555. [Medline] [CrossRef]

8) Kim MS: Influence of neck pain on cervical movement in the sagittal plane during smartphone use. J Phys Ther Sci, 2015, 27: 15-17. [Medline] [CrossRef]

9) Epifanov VA, Zverev VV: [Therapeutic physical exercise in the intensive therapy of patients with injuries to the cervical spine and spinal cord]. Vopr Kurortol Fizioter Lech Fiz Kult, 1987, (2): 52-54. [Medline]

10) Ylinen J, Kautiainen H, Wirén K, et al.: Stretching exercises vs manual therapy in treatment of chronic neck pain: a randomized, controlled cross-over trial. J Rehabil Med, 2007, 39: 126-132. [Medline] [CrossRef]

11) Morgan DL, Proske U: Popping sarcomere hypothesis explains stretch-induced muscle damage. Clin Exp Pharmacol Physiol, 2004, 31: 541-545. [Medline] [CrossRef]

12) Rubini EC, Costa AL, Gomes PS: The effects of stretching on strength performance. Sports Med, 2007, 37: 213-224. [Medline] [CrossRef]

13) Häkkinen A, Salo P, Tarvainen U, et al.: Effect of manual therapy and stretching on neck muscle strength and mobility in chronic neck pain. J Rehabil Med, 2007, 39: 575-579. [Medline] [CrossRef]

14) Zhang FR, He LH, Wu SS, et al.: Quantify work load and muscle functional activation patterns in neck-shoulder muscles of female sewing machine operators using surface electromyogram. Chin Med J (Engl), 2011, 124: 3731-3737. [Medline]

15) Netto KJ, Burnett AF: Reliability of normalisation methods for EMG analysis of neck muscles. Work, 2006, 26: 123-130. [Medline]

16) Strimpakos N, Georgios G, Eleni K, et al.: Issues in relation to the repeatability of and correlation between EMG and Borg scale assessments of neck muscle fatigue. J Electromyogr Kinesiol, 2005, 15: 452-465. [Medline] [CrossRef]

17) Hermens HJ, Freriks B, Disselhorst-Klug C, et al.: Development of recommendations for SEMG sensors and sensor placement procedures. J Electromyogr Kinesiol, 2000, 10: 361-374. [Medline] [CrossRef]

18) Kim GD, Lee KS: Back neck pain rehabilitation customized step-by-step movement. Seoul: Sports Books, 2013.

19) Lee HS, Yoo JH: The effects of stretching and isometric exercise for chronic neck pain patient in strength and pain. Korean Soc Phys Med, 2012 , 7: 329-337. [CrossRef]

20) Hur JG: Effects of neck stabilization exercise to the patients with chronic neck pain. KSR, 2006, 17: 121-133.

21) Shin WS, Park SJ: Basic Fitness Q\&A for a coach. Seoul: Hong Kyeong Publishers, 1997.

22) Gong WT, Cheun HJ, Lee KM: The effect of cervical stabilized exercise and joint mobilization on maximum muscle strength and static muscle endurance of cervical region. JKDIS, 2010, 21: 33-42. 